\title{
A formação de comunidades virtuais no portal Comunique-se: um primeiro olhar
}

\author{
Juliana Lúcia Escobar1 \\ Universidade do Estado do Rio de Janeiro \\ ju.lucia@terra.com.br
}

\begin{abstract}
Resumo: Este artigo investiga especificamente o site "Comunique-se" a fim de verificar se este portal possibilita a formação de comunidades virtuais. Como resultado, foi verificado que o "Comunique-se" oferece condições técnicas que possibilitam a formação de comunidades virtuais na medida em que mantém virtual settlements (lugares delimitados simbolicamente no ciberespaço) nos quais se observa a prática da interação mútua, permitindo duração prolongada (permanência) nas relações entre sujeitos interagentes. Inicialmente, fazemos algumas considerações sobre o conceito de comunidade e algumas alterações por que passou até o contexto atual, em que presenciamos o surgimento de comunidades virtuais. Elaboramos uma definição mínima que inclui alguns pré-requisitos necessários para a formação de comunidades virtuais no ciberespaço.
\end{abstract}

Palavras-chave: Comunidade - Comunidades Virtuais - Interação Mútua

\begin{abstract}
This paper investigates the website "Comunique-se" in order to verify whether it favors the formation of virtual communities. As a result of this investigation, we concluded that the website offers the technical prerequisites that allow the creation of virtual communities, since it engenders "virtual settlements" (symbolically delimited places in cyberspace) wherein one may observe the practice of mutual interaction, allowing for an extended duration (permanence) of the relationship between interacting agents. Notes on the classic concept of community according to authors such as Max Weber, Ferdinand Tönnies, Emile Durkheim and Martin Buber, as well as its current reconfigurations in the context of virtual communities. We seek to elaborate a minimal definition that includes some requisites regarding the formation of virtual communities in cyberspace.
\end{abstract}

\footnotetext{
${ }^{1}$ Mestranda do Programa de Pós-Graduação em Comunicação da Universidade do Estado do Rio de Janeiro (UERJ)
} 
Key words: Community - Virtual Community - Mutual Interaction

Resumen: Esta ponencia investiga el web "Comunique-se" con la finalidad de verificar si favorece la formación de comunidades virtuales. Como resultado de la investigación, uno puede concluir que el website ofrece las condiciones técnicas para la creación de comunidades virtuales, pues engendra "virtual settlements" (espacios simbólicamente delimitados en el ciberespacio) dónde se puede observar la práctica de interacción mutua, lo que permite una duración extendida de las relaciones entre los agentes. Notas sobre el clásico concepto de comunidad según autores como Max Weber, Ferdinand Tönnies, Emile Durkheim and Martin Buber, como también sus transformaciones contemporáneas en el contexto de las comunidades virtuales. Buscamos elaborar una definición mínima capaz de incluir algunos requisitos básicos para la formación de comunidades virtuales en el ciberespacio.

Palabras clave: Comunidad - Comunidades virtuales - Interacción Mutua

Résumé: Cet article étudie le website "Comunique-se" afin de vérifier s'il favorise la formation des communautés virtuelles. Nous avons conclu que le website offre les conditions techniques nécessaires à la création des communautés virtuelles, puisqu'il engendre "des règlements virtuels" (les endroits symboliquement délimités dans Cyberspace) où on peut observer la pratique de l'interaction mutuelle, tenant compte d'une durée prolongée (permanence) du rapport entre les sujets. Notes sur le concept classique de communauté d'après Weber, Ferdinand Tönnies, Emile Durkheim et Martin Buber, aussi bien que sur ses reconfigurations actuelles dans le contexte des communautés virtuelles. Concernant ces communautés, nous cherchons à en élaborer une définition minimale qui indique les conditions de son existence.

Mot clé: Communauté - Communautés Virtuelles - Interaction Mutuelle 


\section{Introdução}

Tal artigo tem como objeto de análise o portal Comunique-se (www.comunique-se.com.br), site cujo conteúdo é voltado para profissionais da área de comunicação. Seu intuito é descobrir se a dinâmica de interatividade proporcionada pelo portal entre os produtores de conteúdo (jornalistas) e os internautas (usuários) permite a formação de comunidades virtuais.

Esperamos com isso contribuir para as discussões acerca das possibilidades reais de estabelecimento de relações sociais através da Web, analisando um caso concreto. Acreditamos que, para o estágio atual dos estudos de cibercultura, é importante investigar os usos efetivos que os agentes humanos vêm fazendo das novas tecnologias que permitem a Comunicação Mediada por Computador (CMC) de modo a confirmar ou refutar tanto as especulações pessimistas quanto as otimistas que suas potencialidades vêm suscitando nos últimos anos.

Alguns estudiosos se dedicam à análise das comunidades virtuais há mais tempo, tendo já empreendido esforços no sentido de estabelecer as ligações entre o conceito tradicional de comunidade e sua transposição para o universo da cibercultura (PRIMO, 1997; LEMOS, 2002; RECUERO, 2002 e 2003). Fazemos aqui inicialmente uma revisão das principais idéias propostas por tais autores, antes de estabelecermos as bases conceituais para empreender a análise do portal Comuniquese.

\section{Comunidade - ontem e hoje}

Objeto sempre presente nas análises e estudos de sociólogos - desde os clássicos e pioneiros desta disciplina como Ferndinand Tönnies, Durkheim e Weber o conceito de comunidade é geralmente acompanhado de denotações positivas, estando associado a coisas e idéias boas, a algo desejável. Conforme Zigmunt Bauman, “o que quer que comunidade signifique, é bom 'ter uma comunidade', 'estar em uma comunidade'.” (BAUMAN, 2003: 7)

Ferdnand Tönnies estabeleceu o conceito de comunidade em oposição ao de sociedade. Tönies considerava que comunidade e sociedade eram dois tipos de vida 
distintos. Em linhas gerais, postulava que, em uma comunidade (Gemeinschaft), os indivíduos agem segundo a tradição e o costume, suas ações são resultado de um talento ou vocação e orientam sua conduta no sentido de garantir a sobrevivência da própria comunidade. Seria, em princípio, o tipo de vida típico do ambiente rural, camponês, ainda com resquícios do período medieval. Já na sociedade (Gesellschaft) - tipo de vida característico da cidade, do ambiente urbano - os indivíduos agem estabelecendo metas e lançando mão dos meios necessários para atingir os fins almejados. Tais meios podem ser inclusive pessoas ou grupos de pessoas. Numa sociedade, as ações são o resultado de uma obrigação externa.

Em suma, servindo-se das próprias palavras de Tönies, a "Gesellschaft é um agregado mecânico e artificial" onde as pessoas "estão por essência separadas, apesar de todos os fatores agregantes" enquanto que a Gemeinschaft é "real e orgânica", um tipo de vivência em conjunto - íntima, privada, e possuidora de exclusividade", "uma vida em comum" onde os indivíduos se mantêm essencialmente unidos, apesar de todos os fatores desagregatórios. (BUBER, 1987:17)

O cruzamento das idéias de Tönies com as de Durkheim permite-nos considerar que comunidade seria o que este último chamou de sociedades simples, nas quais o fator predominante de coesão seria a solidariedade mecânica; enquanto o que Tönies chama de sociedade seria, para Durkheim, as sociedades complexas, onde prevaleceria a solidariedade orgânica. No entanto, como observa Raquel Recuero, Durkheim critica a visão de Tönies para quem a comunidade teria um caráter natural e a sua corrupção é que resultaria na sociedade. "Segundo Durkheim, a sociedade não teria um caráter menos natural do que a comunidade, pois existiriam pequenas semelhanças de atitude nas pequenas aldeias e grandes cidades”. (RECUERO, 2002).

Considerando a diferenciação que Weber faz das relações sociais, entre comunitárias e associativas (e mesmo cientes de que o sociólogo alemão atentasse para o fato de que elementos de um e de outro tipo mesclam-se na maioria das relações sociais), pode-se considerar que, na comunidade töniesiana haveria tendência ao predomínio de relações do tipo comunitária, cujo conteúdo seria "fundado num sentimento subjetivo (afetivo ou tradicional) de pertencimento mútuo que se dá entre as partes envolvidas e com base no qual a ação está reciprocamente referida" (QUINTANEIRO, 1995: 111). Já no que Tönies chama sociedade as relações do tipo associativas tenderiam a ser prevalecentes, uma vez que estas se apóiam 
"num acordo de interesses motivado racionalmente (seja com base em fins ou em valores)...” (QUINTANEIRO, 1995: 111) Segundo Recuero,

No entendimento de Weber, o conceito de comunidade baseia-se na orientação da ação social. Para ele, a comunidade funda-se em qualquer tipo de ligação emocional, afetiva ou tradicional. Weber utiliza como exemplo básico de comunidade a relação. "Chamamos de comunidade a uma relação social na medida em que a orientação da ação social, na média ou no tipo ideal - baseia-se em um sentido de solidariedade: o resultado de ligações emocionais ou tradicionais dos participantes". (Weber 1987:77 in RECUERO, 2002).

Apesar de algumas correlações entre seus pensamentos, Tönies tinha uma visão bem mais romantizada e idealizada de comunidade do que Durkheim e Weber ${ }^{2}$. Mas, mesmo considerando tais diferenças, de modo geral, pode-se identificar elementos comuns na visão clássica do termo, como a idéia de que a autêntica comunidade seria um modo de vida irrecuperável, típico das primeiras agregações humanas, pertencentes ao passado. A ele estão associadas idéias e conceitos como os de tradição, costume, sobrevivência, caráter natural (Tönies); em uma comunidade o principal fator de coesão seria a solidariedade mecânica, ou seja, os indivíduos seriam solidários devido às suas similitudes (Durkheim); entre as pessoas, tenderia a prevalecer relações do tipo comunitária (sentimental, afetiva) baseadas na solidariedade, resultado de ligações emocionais ou tradicionais (Weber).

O modo de vida comunitário estaria sendo suplantado com a instauração e consolidação da modernidade e de uma racionalização que passa a regular todas as esferas da convivência humana (econômica, política, social). As transformações pela quais vinham passando as relações sociais, agora desenvolvidas num ambiente urbano e não mais rural, fariam parte de um processo irreversível. Foi preciso então buscar as novas bases sobre as quais poderia se fundar um outro conceito de comunidade, tendo em vista a forma (ou as formas) de experimentação de uma vida comunitária possibilitada (s) pela modernidade. Proximidade territorial, interesses e sentimentos compartilhados, objetivos comuns passam a figurar entre os elementos

\footnotetext{
${ }^{2}$ Para uma revisão mais extensa do pensamento de Tönnies sobre a diferença entre comunidade e sociedade, assim como as concordâncias e discordâncias de Durkheim e Weber com as idéias de Tönnies sobre comunidade, ver RECUERO, Raquel Comunidades Virtuais: Uma Abordagem Teórica. Artigo apresentado no V seminário Internacional de Comunicação, GT de Tecnologia das Mídias. (outubro de 2002). Disponível em $<$ http://www.pontomidia.com.br/raquel/teorica.htm>(02/08/2002)
} 
de coesão que deveriam ser observados na sociedade capitalista, industrial, normativa, burocratizada, ao se pretender delimitar o que era uma comunidade. $\mathrm{O}$ elemento geográfico especificamente ganha um certo peso, uma vez que é mais provável haver objetivos em comum e fatores de identificação entre aqueles indivíduos que compartilhem um mesmo ambiente físico (bairro, vizinhança, cidade, nação). Esta proximidade seria a condição para o estabelecimento de relações.

Martin Buber (1878/1965), estudioso judeu com atuação política em movimentos de esquerda, cujos estudos tiveram penetração em diferentes áreas como filosofia, sociologia, pedagogia e religião, teve uma preocupação constante com o conceito de comunidade e suas ramificações. Para Buber, uma "nova comunidade" deveria estar baseada, entre outras coisas, "em relações emanadas da livre escolha das pessoas e não de ligações consangüíneas", (BUBER, 1987: 17). Indo contra a ordem utilitarista que já dominava a sociedade de seu tempo, insiste que a "comunidade deve ser um fim em si mesma e não um instrumento para chegar a outros fins". (ibidem: 25) Buber (cuja obra mais conhecida é Eu e Tu) teve entre seus mestres Simmel e entre suas referências, o socialismo utópico e o pensamento de Nietzsche, mas, principalmente as idéias de Ferdinand Tönnies. Enquanto este via a comunidade como o paraíso original perdido, Buber a enxergava como um novo paraíso a ser construído, fosse com a união dos homens sob o signo comum da terra, do trabalho, da ajuda ou do espírito (religião).

$\mathrm{Na}$ contemporaneidade (ou pós-modernidade, para uns ou ainda, para outros, modernidade tardia), novos elementos, além da questão territorial e do compartilhamento de algo em comum, foram sendo acrescidos à idéia de comunidade. Recuero (2002) enumera algumas características de uma comunidade segundo Palácios: "o sentimento de pertencimento, a territorialidade, a permanência, a ligação entre o sentimento de comunidade, caráter corporativo e emergência de um projeto comum, e a existência de formas próprias de comunicação”. A estudiosa também lembra a separação que Beamish faz do conceito em dois aspectos - o da territorialidade e o do interesse comum - de modo que o primeiro não é mais condição para a existência das relações entre as pessoas (RECUERO, 2002). 


\section{Comunidade Virtual - uma problemática contemporânea}

Atualmente, com a disseminação das novas tecnologias de comunicação, notadamente a Internet, devemos, como assinalou André Lemos

pensar a aplicabilidade do conceito [de comunidade] aos agrupamentos eletrônicos da cibercultura como listas de discussão, salas de bate-papo, newsgroups e websites. Muito se tem falado da possibilidade do ciberespaço gerar afinidades que poderiam ser caracterizadas como comunidades. (LEMOS, 2002)

Para Pierre Lévy3, o virtual não se contrapõe ao real mas sim ao atual. O virtual seria uma problemática que teria como resposta a atualidade. Já o real se contraporia ao possível, algo que já está resolvido e que, diante de determinadas circunstâncias, vai ocorrer, uma vez que é uma solução pré-definida. Assim, ao se falar em comunidade virtual está-se acrescentando ao conceito de comunidade uma nova problemática. Ao analisar se determinado site constitui-se como uma comunidade ou dá meios para a formação de uma, estaremos investigando se ele se apresenta como uma solução em potencial para esta problemática, se pode ser considerado uma forma de atualização da comunidade4.

Um dos esforços no sentido de propor uma definição conceitual para comunidade virtual foi feito por Raquel Recuero, no artigo "Comunidades Virtuais: Uma Abordagem Teórica” (ver bibliografia). A territorialidade, para alguns estudiosos, condição primordial para se falar de comunidade, é um dos aspectos problematizado pela autora. Neste ponto, cabe-nos uma breve revisão da constituição do conceito de ciberespaço, entendido como o lugar próprio da virtualidade, dos ambientes "habitados" pelos que utilizam a CMC.

Da mesma maneira que todos os meios de comunicação precedentes, o computador redefiniu o modo como o homem se relaciona com as variantes espaço e tempo. Após um novo conceito, um novo tratamento do tempo que foi sendo construído durante séculos no desenvolvimento das mídias, começou a se desenrolar uma alteração ou, de outro modo, a se apresentar uma alternativa no que diz respeito

\footnotetext{
3 Ver sua obra "O que é o Virtual"

4 Retomaremos abaixo esta contraposição entre virtual/atual e possível/real apresentada por Pierre Lévy ao falarmos dos conceitos de interação mútua e interação reativa propostos por Alex Primo.
} 
à relação do homem com o espaço em que vive e no qual atua e interage. $\mathrm{O}$ computador introduz um novo conceito de espaço ao inaugurar o ciberespaço.

Conforme Margaret Wertheim

De maneira especialmente proeminente, o ciberespaço é um novo lugar para o convívio social e o jogo. Salas de conversa, grupos de discussão, canais de IRC, conferências e fóruns on-line, além dos mundos de fantasia conhecidos como MUDs - tudo parece prometer um campo quase infinito para a interação social." (WERTHEIM, 2001: 166)

Wertheim chama a atenção para o fato de estarmos diante de um fenômeno que recoloca o significado da palavra espaço para além das bases geográficas. $\mathrm{O}$ ciberespaço é uma arena "que possui sua própria lógica e geografia" que embora diferente de tudo já experimentado até hoje "não se torna menos real por não ser material". A autora enfatiza que "Embora destituído de fisicalidade, o ciberespaço é um lugar real. Eu estou lá - seja qual for o significado final desta afirmação.” (ibidem: 169)

Nas palavras de André Lemos (1996) o ciberespaço é uma "nova dimensão espaço-temporal" e

Mesmo sem ser uma entidade física concreta, pois ele é um espaço imaginário, o cyberespaço constitui-se em um espaço intermediário. Ele não é desconectado da realidade mas, ao contrário, parte fundamental da cultura contemporânea. O cyberespaço é assim um complexificador do real. (LEMOS, 1996)

Atualmente, para além do ao vivo televisionado, que permite o acesso ao acontecimento no exato momento em que ele ocorre; mais do que a recepção pura e simples, o que o computador nos coloca, ao instituir este novo lugar que é o ciberespaço, é a possibilidade de interferência na mensagem que recebemos no exato momento em que esta é emitida: é a interatividade (também indispensável, como veremos mais adiante, quando se fala no estabelecimento de uma comunidade virtual).

Seguindo a proposta de Quentin Jones, Recuero adota o conceito de virtual settlement (estabelecimento virtual), entendido como um lugar simbólico, situado no ciberespaço, que teria a função desta territorialidade necessária para a constituição de laços comunitários entre os indivíduos. É um delimitador de 
fronteiras simbólicas e não concretas. Funciona como o suporte para a verdadeira comunidade virtual e é imprescindível para que esta se forme. No entanto, a mera existência de um virtual settlement não garante o estabelecimento de uma comunidade virtual. Uma sala de bate-papo, por exemplo, é um virtual settlement mas somente dará origem a uma verdadeira comunidade virtual se as pessoas de fato utilizarem este lugar no ciberespaço para a criação e manutenção de laços e relações sociais. Comunidades virtuais surgem a partir dos usos que as pessoas fazem de um determinado virtual settlement.

No ciberespaço, diante de um virtual settlement, embora cada internauta esteja fisicamente situado em um local diferente, todos estão habitando a tela. Desta forma, a dispersão do público, o distanciamento dos receptores entre si, que teria sido incentivado pela TV, é recolocado pelo computador, podendo agora significar o contrário: concentração ou ainda interação.

A tela se constitui apenas como mais um dos instrumentos que compõem todo um complexo estrutural que auxilia o homem na redefinição de suas relações espaço-temporais. Agora, o homem relaciona-se com seus semelhantes e com um novo objeto - o computador - que o (re)coloca em contato com outros homens. No entanto, a novidade que o computador traz ao inaugurar o ciberespaço, o espaço da tela, é permitir que o receptor "fale", "ouça", "aja", participando ativamente da vida que se desenrola neste "novo lugar". Em última análise, permite que ele interaja com seus semelhantes.

Assim como o virtual settlement, outro requisito apontado por Recuero em sua definição de comunidade virtual é a prática da interação mútua, conceito proposto por Alex Primo (1998), em contraposição ao de interação reativa. Tal autor defende que "a relação no contexto informático, que se pretende plenamente interativa, deve ser trabalhada como uma aproximação àquela interpessoal". Baseando-se em estudos de comunicação interpessoal Primo estrutura seus conceitos tendo em vista sete características: sistema, processo, operação, fluxo, throughput, relação e interface. 


\section{Interação mútua}

Caracteriza-se como um sistema aberto, com elementos interdependentes, de modo que o sistema é modificado quando um deles é afetado. Nas palavras do autor

... os sistemas interativos mútuos estão voltados para a evolução e desenvolvimento. E por engajar agentes inteligentes, os mesmos resultados de uma interação podem ser alcançados de múltiplas formas, mesmo que independente da situação inicial do sistema (princípio da eqüifinalidade) (PRIMO, 1998)

Neste tipo de interação, "o relacionamento evolui a partir de processos de negociação" (PRIMO, 1998 grifo nosso), com resultados imprevistos. A operação se dá por meio de ações interdependentes, entre agentes ativos e criativos que influenciam uns os comportamentos dos outros. Assim "a cada evento comunicativo, a relação se transforma”.

O throughput (aquilo que, segundo o autor, se passa entre uma ação input - e uma reação - output) é marcado por um diálogo em que as informações inseridas pelos interagentes ou mesmo pela ambiente são decodificadas e interpretadas podendo gerar novas codificações. "Cada interpretação se dá pelo confronto da mensagem recebida com a complexidade cognitiva do interagente. Mesmo que ele perceba algo que não conhece, a confrontação se dá com aquilo que ele conhece".

Os sistemas de interação mútua se caracterizam por seu fluxo dinâmico e em desenvolvimento, e quanto à relação, se valem da construção negociada, "a relação é constantemente construída pelos interagentes". Primo as classifica então como um processo emergente que "vai sendo definida durante o processo". Os efeitos de uma ação não podem ser pré-determinados. Assim, tais sistemas se calcam no relativismo.

Com base nas definições de Deleuze e Lévy, segundo os quais “o virtual é um complexo problemático, enquanto o potencial é um conjunto de possíveis que aguardam por sua realização" (PRIMO, 1998) o autor sugere que, no que diz respeito à interface, "sistemas interativos mútuos se interfaceiam virtualmente, enquanto os sistemas reativos apresentam uma interface potencial". Explicando melhor, nas palavras do próprio Alex Primo: 
Para que uma interface seja plenamente interativa, ela necessita trabalhar na virtualidade, possibilitando a ocorrência da problemática e viabilizando atualizações. Por outro lado, uma interface reativa resume-se ao possível, que espera o clique do usuário para realizar-se. A tela está ali, completamente programada e perfeita para disparar um mecanismo ou uma nova tela que espera por seu destravamento. Como o possível é o real na espera da existência, isto é, já está completamente constituído no limbo esperando ser realizado (Lévy, 1996), não se pode pensar uma interface dessas como mutuamente interativa. A interatividade mútua depende da virtualização, da problemática. Já interfaces potenciais são tão reativas que podem ter sua realização prétestadas. Existem programas que podem analisar todos os links possíveis e presentes e averiguar se conduzem corretamente àquele novo item ou àquela nova página ou seção pretendidos. Logo, percebe-se que esse tipo de interface se resume ao possível. O usuário apenas transita pelo pré-resolvido, pelo pré-testado, disparando o inevitável. Nessas interfaces é preciso contentar-se com a potencialização do real. Um real que esteve sempre prestes a se mostrar. Por outro lado, uma interface de interação mútua cria o cenário para a problematização, um ambiente virtual onde acontecerão diversas atualizações. Portanto, a interatividade plena depende do virtual. (PRIMO, 1998)

Assim, podemos resumir as diferenças entre a interação mútua e a interação reativa, a partir das sete características destacadas por Alex Primo no seguinte quadro:

\begin{tabular}{|l|l|}
\hline \multicolumn{1}{|c|}{ Interação Mútua } & \multicolumn{1}{c|}{ Interação Reativa } \\
\hline Sistema aberto & Sistema fechado \\
\hline Processo de negociação & Processo se resume ao par estímulo-resposta \\
\hline $\begin{array}{l}\text { Operação com ações } \\
\text { interdependentes }\end{array}$ & Operação limita-se a ação e reações programadas \\
\hline Fluxo com seqüência indefinida & Fluxo com seqüência definida \\
\hline $\begin{array}{l}\text { Throughput caracterizado pelo } \\
\text { diálogo }\end{array}$ & $\begin{array}{l}\text { Throughput caracterizado por reflexos ou } \\
\text { automações }\end{array}$ \\
\hline $\begin{array}{l}\text { Relação construída durante o } \\
\text { processo }\end{array}$ & $\begin{array}{l}\text { Relação causal (cada reação é causa de uma ação pré- } \\
\text { determinada) }\end{array}$ \\
\hline Interface virtual & Interfacial potencial \\
\hline
\end{tabular}

Acreditamos, assim como Recuero e Primo, que um verdadeiro "interagir" no universo virtual da Internet só é possível através da interação mútua, que realmente permite haver interferência, intercâmbio e diálogo no processo comunicativo no exato momento em que ele ocorre. Ao inserir a velocidade e a 
simultaneidade entre as ações dos interagentes de um processo de troca de informações mediadas por computador, pode-se dizer que a Web tenha possibilitado uma reconquista da co-presença entre emissores e receptores. Co-presença perdida no momento em que a cultura oral foi substituída pela tradição escrita e o receptor pode estar separado, no tempo e no espaço, do emissor. O que o homem faz hoje, através do computador, é instaurar um novo espaço, baseado nas tecnologias intelectuais disponíveis em nosso tempo. Assim como faziam os membros das sociedades sem escrita, estamos utilizando as melhores estratégias de codificação que estão à nossa disposição. Nossos parâmetros são outros, não mais os do mundo físico, materialmente habitado, e sim, os de um mundo virtual, habitado por imagens e símbolos de uma outra ordem; diferentes daqueles que sempre habitaram o mundo da linguagem humana até hoje.

\section{Comunique-se e a formação de comunidades virtuais: um primeiro olhar}

O Comunique-se é um site voltado para profissionais da área de comunicação que oferece, além de conteúdo informativo produzido por sua equipe de jornalistas e colunistas, ferramentas remotas que auxiliam o trabalho de empresas e de assessores de imprensa (como coletiva on line, distribuidor de release, sugestão de pautas on line) e mecanismos que auxiliam o aprimoramento profissional (cursos on line). Constitui-se como um portal vertical, ou seja, de conteúdo especializado e, segundo informação divulgada pelo próprio site ${ }^{5}$, foi ao ar em setembro de 2001 como o primeiro portal brasileiro totalmente voltado para profissionais de comunicação. Tem como missão "divulgar notícias de bastidores do mercado jornalístico brasileiro, colocar em discussão aspectos práticos e éticos da profissão, além de fornecer ferramentas de apoio para o trabalho diário dos jornalistas de todo o país".

Passamos, a partir de agora, a avaliar se, de fato, podem formar-se comunidades virtuais a partir do uso das ferramentas e mecanismos disponibilizados pelo site Comunique-se. Para empreender tal análise tomaremos como base a conceituação de comunidade virtual proposta por Raquel Recuero, explicitada na seção anterior deste artigo. Nosso intuito é verificar se o portal oferece condições

5 Ver página "Sobre o Comunique-se" (http://www.comuniquese.com.br/sobreocomuniquese.asp) 
para que "as pessoas estabeleçam entre si relações sociais", condição primordial, segundo a pesquisadora, para se falar em constituição de comunidades. Para isto, vamos considerar, além dos dois aspectos detalhados (virtual settlement e interação mútua), um terceiro: a permanência - entendida, conforme anteviu Palácios, segundo a autora, como espaço temporal contínuo de relacionamento.

A primeira condição a se considerar é se o portal constitui-se como um virtual settlement, ou seja, como um "lugar" no ciberespaço em que as pessoas podem se encontrar, funcionando como o suporte para a comunidade virtual. Consideramos que todas as oito subseções da seção "Jornal da Imprensa" constituem-se como virtual settlements, quais sejam: "10 Caderno", "Colunas", "Em Pauta”, "Vaivém”, “Prefácio”, “Carreira”, "Papo na Redação” e "Perfil”.

Tais subseções possuem o sistema de comentários, que funciona como um fórum no qual os usuários incluem mensagens a partir do texto original disponibilizado pelo site. Já o "Papo na Redação", além de contar com este mecanismo, funciona como um chat. É realizado uma vez por semana em sistema de entrevista no qual os usuários podem conversar diretamente com o entrevistado, enviando perguntas em tempo real. Após a realização da entrevista, o texto integral é disponibilizado no site, quando passa a contar com a área destinada aos comentários dos leitores.

Também identificamos como virtual settlements três das quatro subseções da seção "Comunidade" 6: "Blog-se", "Chat" e "Comunicador".

O "Blog-se" é o servidor de $b \log s^{7}$ do portal, no qual os usuários podem criar seus diários virtuais e, através deles, estabelecer contato com outros usuários. O "Chat" é uma sala de bate-papo e o "Comunicador", uma ferramenta que possibilita a troca instantânea e on line de mensagens entre os usuários conectados (funciona

\footnotetext{
${ }^{6}$ A subseção que não consideramos como um virtual settlement é "Clube do Usuário", destinada a divulgar descontos e promoções especiais oferecidas aos usuários do Comuniquese por parceiros do site.

7 Weblog (ou simplesmente blog) é modelo automatizado de publicação de sites, baseado em pequenas inclusões diárias (os chamados posts) em que as informações são dispostas de modo que a mais recente esteja sempre no topo, em evidência. Inicialmente considerados meros diários virtuais utilizados sobretudo por adolescentes, os blogs vêm ganhando cada vez mais espaço no universo jornalístico.
} 
como outras conhecidas ferramentas de comunicação em tempo real, como ICQ e Messanger).

Consideramos então que tanto as subseções que disponibilizam uma área específica para comentários dos internautas, como o servidor de blogs, a sala de chat e o comunicador se constituem como virtual settlements, ou seja, "lugares" simbólicos no ciberespaço onde os jornalistas e os usuários ${ }^{8}$ podem interagir, dialogar e assim trocar opiniões e impressões.

Nestes mesmos ambientes o segundo elemento que estamos considerando para esta análise, a interação mútua, estaria presente, já que se constituem como sistemas abertos; em que existe um processo de negociação entre agentes ativos e criativos marcado pelo diálogo, ou seja, cada interagente interpreta uma ação antes de responder a ela de modo que o out put não é um ato puramente reativo; o fluxo é dinâmico, emergente, uma vez que a relação é constante e vai sendo construída durante o desenrolar do processo e, por fim, as interfaces são virtuais, permitindo respostas novas e criativas e não apenas uma gama limitada e pré-definida pelo sistema.

O terceiro e último elemento a ser considerado é a permanência entendida por Recuero como o plano temporal necessário para que haja o aprofundamento das relações sociais entre uma variedade de comunicadores de modo a possibilitar que se chegue a uma estabilidade de membros, e assim permitir-se a constituição de uma verdadeira comunidade virtual. A permanência seria uma das condições para que se forme, entre os membros, um sentimento de pertencimento, também necessário para a constituição de comunidades (e não só as virtuais).

A observação durante um mês do conteúdo do "Informativo Comunique-

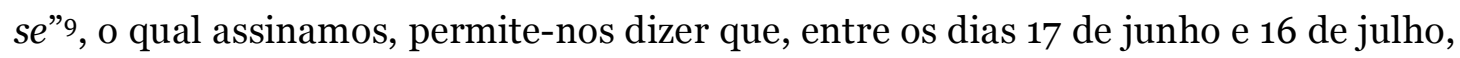
ou seja, no espaço de um mês, em 19 dias houve novas publicações em pelo menos duas das subseções da seção "Jornal da Imprensa"(10 Caderno, Colunas, Em pauta,

\footnotetext{
8 Para inserir comentários é preciso ser um usuário cadastrado no site, possuindo um nome de usuário e senha que devem ser informados na página de abertura do portal para que se possa navegar por ele. O próprio site denomina como usuário os internautas cadastrados. Além de inserir comentários, apenas tais usuários podem utilizar as demais ferramentas disponibilizadas pelo site, tais como o servidor de blogs e o comunicador.

9 Informativo enviado, gratuitamente, por e-mail, aos usuários assinantes, ou seja, que tenham expressado o desejo de o receber.
} 
Vaivém, Prefácio, Carreira, Papo na Redação, Perfil.) ${ }^{10}$. Ou seja, novos temas e assuntos são publicados quase diariamente, possibilitando que haja a permanência nos termos aqui definidos: com as seções sendo constantemente atualizadas, apresentando novos conteúdos, o portal fornece aos usuários elementos para que as relações estabelecidas através do diálogo com outros usuários e com os próprios jornalistas do site tenham continuidade no tempo podendo ser aprofundadas.

Já pela observação do conteúdo publicado, nota-se que enquanto alguns temas não suscitam comentário algum dos usuários, outros geram uma quantidade razoável de manifestações. Isto nos leva a considerar uma outra característica importante para o pertencimento na comunidade virtual (Recuero, 2003 - citando Palácios): a eletividade. No Comunique-se, o leitor cadastrado e assim considerado usuário pode escolher livremente sobre qual entre os assuntos disponibilizados quer fazer seu comentário ou, dito de outra forma, em qual destas "comunidades" quer se inserir. Numa observação preliminar, nota-se que alguns usuários participam, de fato, de mais de um destes virtual settlements disponibilizados pelo portal. O usuário Jonas dos Santos Marcondes, por exemplo, no dia 28 de julho de 2005, inclui seus comentários em duas Colunas: "Jornalistas \& Cia"11 e "Jornalismo Online"12.

O termo eletividade pode ser associado ao que Michel Maffesoli chama, em "O Tempo das Tribos", de socialidade eletiva. O sociólogo francês destaca a importância do que chama de histórias quotidianas.

A sociedade assim compreendida não se resume numa mecanicidade racional qualquer. Ela vive e se organiza, no sentido estrito do termo, através dos reencontros, das situações, das experiências no seio dos diversos grupos a que pertence cada indivíduo. Estes grupos se entrecruzam uns com os outros e constituem, ao mesmo tempo, uma massa indiferenciada e polaridades muito diversificadas. (MAFFESOLI, 1987: 121).

\footnotetext{
${ }^{10}$ No período citado, (17 de junho a 16 de julho de 2005), foram enviadas 19 edições do informativo (além de algumas extraordinárias, sobre assuntos específicos). Para esta análise, consideramos estas 19 edições, referentes cada qual a um dia diferente. Note-se que neste período, o informativo não foi enviado nos finais de semana (sábado e domingo) e em um ou outro dia da semana específico. Desconhecemos o motivo desta irregularidade no envio de tal informativo.

${ }^{11} \mathrm{http}: / /$ www.comunique-

se.com.br/conteudo/newsshow.asp?op2=\&op3=\&editoria $=12 \&$ idnot $=23077$

$12 \mathrm{http}: / /$ www.comunique-

se.com.br/conteudo/newsshow.asp?op2=\&op3=\&editoria $=135 \&$ idnot $=23052$
} 
Em artigo mais recente (2003), em que postula que a "comunicação é cimento social" Maffesoli afirma que "na prática, a informação só consegue unir microgrupos, microcosmos, universos segmentados" e que "A informação e a comunicação, no sentido de partilha de emoções e de sentimentos, só podem dirigirse a tribos que comungam em torno de um totem". Um portal vertical como o Comunique-se apresenta-se justamente assim, como um microcosmos, um universo segmentado dirigido a uma tribo (seu público alvo: os profissionais de comunicação) que .comunga em torno do totem comum: a profissão escolhida.

Outro fator que pode nos levar a considerar que a característica de permanência está presente no Comunique-se é a constatação de que pelo menos alguns membros participam de determinadas comunidades há um tempo superior há um ano. É o caso de usuários como Jorge Henrique Cordeiro (Subeditor do Globo on line) e João Pequeno Bandeira de Melo que se manifestaram na coluna "Link SP" assinada pelo jornalista José Paulo Lanyi numa edição de $2003^{13}$ e voltaram a se manifestar em 2005, quando uma outra edição da coluna retomava o assunto tratado dois anos antes ${ }^{14}$. Reconhecemos, no entanto, que seria necessário um estudo mais sistemático para comprovar se esta situação se repete mais vezes e com uma variedade de usuários suficiente para podermos considerar tal constatação válida para outros vitual settlements constituídos no Comunique-se.

\section{Considerações finais}

Após identificarmos a existência de alguns virtual settlements no site Comunique-se - o que consideramos condição técnica para a constituição de comunidades virtuais -, comprovamos também que o portal possibilita a efetivação da interação mútua, concretizada a partir do uso efetivo que jornalistas do próprio site e usuários fazem das ferramentas e mecanismos interativos disponibilizados. A partir de nossa observação do site (como usuária há anos e como pesquisadora há meses) atestamos que o diálogo e a troca de opiniões, impressões e argumentos é prática real e constante no portal.

\footnotetext{
13 http://www.comunique-se.com.br/conteudo/newsshow.asp?editoria=8\&idnot=8847

14 http://www.comunique-

se.com.br/conteudo/newsshow.asp?op2=\&op3=\&editoria $=240 \&$ idnot $=22679$
} 
No entanto, embora haja alguns indícios de que haja permanência nas relações estabelecidas entre os usuários e jornalistas do Comunique-se, consideramos que é preciso um estudo mais aprofundado sobre este aspecto para podermos dizer se as relações estabelecidas por tais interagentes são profundas o suficiente para darem origem a comunidades virtuais nos termos propostos pela pesquisadora Raquel Recuero.

Para constatar se constituem-se verdadeiras comunidades virtuais a partir das relações entre os interagentes que "freqüentam" o portal Comunique-se consideramos ser preciso realizar uma análise mais aprofundada, que inclua um acompanhamento mais sistemático da dinâmica interativa do site, além de entrevistas pessoais com os interagentes. Este é um novo passo que poderemos dar no caminho que iremos seguir durante a produção da dissertação de mestrado que terá o portal como objeto de estudo.

Tratamos aqui, como nos propusemos, de investigar se a dinâmica de interatividade proporcionada pelo portal entre os produtores de conteúdo (jornalistas) e os internautas (usuários) permite a formação de comunidades virtuais. Ao cabo de nossa análise, constatamos haver condições técnicas apropriadas para tal.

\section{Referências:}

BAUMAN, Zygmunt. Comunidade: a busca por segurança no mundo atual. Rio de Janeiro: Jorge Zahar Ed., 2003.

BAUMAN, Zygmunt. Globalização: as conseqüências humanas. Rio de Janeiro: Jorge Zahar Ed., 1999.

BUBER, Martin. Sobre Comunidade. Coleção Debates. Editora Perspectiva. São Paulo, 1987. 
LEMOS, André. Agregações Eletrônicas ou Comunidades Virtuais? Análise das Listas Facom e Cibercultura. Disponível on line em http://www.facom.ufba.br/ciberpesquisa/404nOtFound/404_14.htm

. As Estruturas Antropológicas do Ciberespaço. Disponível on line em http://www.facom.ufba.br/pesq/cyber/lemos/estrcy1.html

Ciber-Socialidade. Tecnologia e Vida Social na Cultura

Contemporânea. Disponível on line em

http://www.facom.ufba.br/ciberpesquisa/txt_and3.htm

LÉVY, Pierre. As tecnologias da inteligência - o futuro do pensamento na era da informática. Rio de Janeiro: Ed. 34, 1993. . O que é o virtual? São Paulo: Ed. 34, 1996.

MAFFESOLI, Michel. O tempo das tribos - o declínio do individualismo nas sociedades de massa. Rio de Janeiro, Forense-Universitária, 1987.

. A comunicação sem fim (teoria pós-moderna da comunicação). Revista da FAMECOS, Porto Alegre, v.20, p. 13-20, 2003.

PRIMO, Alex F. T. Interação Mútua e Interação Reativa. Texto apresentado no GT de Teoria da Comunicação para apresentação do XXI Congresso da Intercom Recife, PE, de 9 a 12 de setembro de 1998. Disponível on line em http://www.psico.ufrgs.br/ aprimo/pb/intera.htm . A Emergência das Comunidades Virtuais. Texto apresentado no GT de Teoria da Comunicação no XX Congresso da Intercom - Santos, SP, 1997.

Disponível on line em http://usr.psico.ufrgs.br/ aprimo/pb/comuni.htm . e RECUERO, Raquel. Hipertexto Cooperativo: Uma análise da escrita coletiva a partir dos blogs e da wikipedia. Revista da FAMECOS, Porto Alegre, v. 22, p. 54-65, 2003.

QUINTANEIRO, T. et al. Um toque de clássicos: Durkheim, Marx e Weber. Belo Horizonte, Ed. UFMG, 1995.

RECUERO, Raquel da Cunha. Weblogs, Webrings e Comunidades Virtuais. Disponível on line em http://www.facom.ufba.br/ciberpesquisa/404nOtFound/404_31.htm . Comunidades Virtuais: Uma Abordagem Teórica. Artigo apresentado no V seminário Internacional de Comunicação, GT de Tecnologia das Mídias. (outubro de 2002). Disponível em <http://www.pontomidia.com.br/raquel/teorica.htm>(02/08/2002)

RHEINGOLD, Howard. The Virtual Community. Homestanding On The Electronic Frontier. 1993 On line, disponível em http://www.rheingold.com/vc/book/

WERTHEIM, Margaret. Uma história do espaço de Dante à Internet. Rio de Janeiro. Jorge Zahar Ed., 2001. 